\title{
Salivary Cortisol in Relation to the Use of Information and Communication Technology (ICT) in School-Aged Children
}

\author{
Marjut Wallenius $^{1,2}$, Ari Hirvonen ${ }^{3}$, Harri Lindholm ${ }^{4}$, Arja Rimpelä ${ }^{5}$ Clas-Hakan Nygård ${ }^{5}$, Lea \\ Saarni ${ }^{5}$, Raija-Leena Punamäki ${ }^{1}$ \\ ${ }^{1}$ Department of Psychology, University of Tampere, Tampere, Finland; ${ }^{2}$ Research Unit of Pirkanmaa Hospital District, Tampere \\ University Hospital, Tampere, Finland; ${ }^{3}$ Biomonitoring Laboratory, Finnish Institute of Occupational Health, Helsinki, Finland; \\ ${ }^{4}$ Department of Physiology, Finnish Institute of Occupational Health, Helsinki, Finland; ${ }^{5}$ Tampere School of Public Health, Univer- \\ sity of Tampere, Tampere, Finland. \\ Email: marjut.wallenius@uta.fi
}

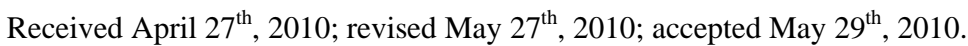

\begin{abstract}
Long periods of use of Information and Communication Technology (ICT) may raise strong emotions and lead to cognitive fatigue. The current study focused on the impact of ICT use the preceding day on the next-day salivary cortisol pattern in 72 school-aged children (39 at the age ten and 33 at the age 13). Salivary cortisol levels were measured at five time points from awakening to bedtime. Time spent in different ICT activities the day before salivary sampling was measured by an activity diary. Results showed that the participants who had used ICT on an average three hours the preceding day showed a significantly reduced cortisol increase one hour after awakening (awakening response) compared to those who had used ICT not at all or less than one hour after controlling for pubertal status and the level of depression. The results suggest a stress response as a consequence of a long period of ICT use.
\end{abstract}

Keywords: ICT, Salivary Cortisol, Stress, Children, Adolescents

\section{Introduction}

Information and communication technology (ICT; mobile phone, digital games, computer, the Internet) is matching the popularity of traditional media in the lives of Western children and adolescents. Recent findings show that digital game playing exceeds time spent in television viewing among children [1]. Younger children and boys spend more time in digital game playing while adolescents (14-18 years) spend increasingly time in Internet surfing and chatting [2,3]. ICT use serves many motives and functions among children and adolescents. For example, digital game playing offers restoration, social compensation as well as possibilities to experience and learn new or escape worries [4]. Thus, ICT may provide an extra dimension to life in which children and adolescents are able to accomplish things which are not possible for them

\footnotetext{
*This research was supported by the grants from the Academy of Finland (201669), the Information Society Institute of the University of Tampere and the Tampere University of Technology (16-01), and the Competitive Research Funding of the Pirkanmaa Hospital District (9G211).
}

in reality [5]. The psychophysiological effects of daily ICT use among children and adolescents have not been studied so far. In this study, we examine relations between the intensity of daily ICT use and psychophysiological stress indicated by diurnal salivary cortisol secretion in school-aged children.

Interactions with ICT can be understood as mental tasks which may comprise different components [6]. These interactions may elicit strong emotional responses, such as enthusiasm, fear, and surprise, affect the individual's arousal level, and demand voluntary, directed attention and cognitive processing. Although adolescents experience the different ICT activities mainly positively, long-lasting use of ICT may, however, result in more negative consequences, such as directed attention fatigue [7] and heighten arousal level which is often antecedents of physiological stress response [7]. Directed attention fatigue as a result of prolonged period of mental effort is independent of the content of a task [8]. Physiological measures of stress can be seen even after a long period of a pleasant task [9]. Thus, the mental tasks during ICT use, 
although experienced positively, may cause stress. In addition, findings suggest that the auditory input, such as built-in music during video game playing, may contribute significantly to the stress response [10]. Recovery from directed attention fatigue occurs during sleep and during involuntary attention, or fascination, requiring no effort, for instance in nature environments [11]. In everyday life children and adolescents may use multiple forms of ICT daily or even at the same time. Also, directed attention is needed most of the time during schooldays and when doing home works. We hypothesize that directed attention fatigue is increased by increasing the total time used in ICT. We further hypothesize that psychophysiological stress results as a consequence of directed attention fatigue and insufficient attentional resources with joint effect of possible other stress-related features of ICT interactions, such as high arousal level and noise.

When an individual is exposed to stress, a cascade of physiological events occur along the hypothlamic- pituitary-adrenal (HPA) axis. Subsequent release of the steroid hormone cortisol is considered the body's major neuroendocrine response to stress [12]. Prior research among children and adolescents shows that the daily rhythm characteristic to cortisol can be disrupted by psychological and environmental influences, such as cumulative environmental risks [13], poverty [14], day-care [15], post-traumatic stress disorder [16], social deprivation [17], performance challenge [18], and violence exposure [19].

In the diurnal profile of cortisol secretion, the cortisol awakening response (CAR) has been recognised as a distinct phenomenon. Under basal conditions, cortisol secretion follows a circadian rhythm, manifested in $50-160 \%$ increase in salivary-free cortisol during the first 30-40 min after awakening, drop rapidly in the next few hours and then more gradually throughout the day [20]. The cortisol awakening response has shown to be an intra-individually stable phenomenon [21]. A majority (70\%) of 10-12-year-old children show a cortisol awakening rise, although lower than in adults, with higher levels in girls than boys [22,23]. Results concerning raltions between cortisol measures and pubertal stage are somewhat contradictory. While some studies have found no relationships [22,23], some findings show correlations between higher pubertal stage and elevated cortisol curves and lower cortisol awakening response [24]. The cortisol awakening response is unrelated to the mean underlying level of cortisol secretory activity throughout the rest of the day [25].

Many studies have found perceived stress to be linked to some aspects of the cortisol awakening response for a review see [20]. Especially the attenuated cortisol awa kening response is related to stress, such as acute [26] and long-lasting stress [27], chronic fatigue [28], early loss experience [29] and violence exposure [19]. Contrary to adult studies, adolescents with higher levels of depressive symptoms showed lower diurnal cortisol levels [24].

Results on the association between ICT use and cortisol levels are limited, describing only short-term experimenttal conditions concerning digital playing. Some studies have found raised cortisol levels [30] but others have found no chance during a digital game [31]. Still some results suggest that higher cortisol levels are due to built-in music of digital games [10]. Instead, psychophysiological effects of daily ICT use have not been studied.

The present study investigated whether the amount of time used on ICT the preceding day was related to salivary cortisol among school-aged children. For cortisol, we used both levels and dynamics of cortisol concentration. We hypothesized that higher ICT use the preceding day is related to higher total cortisol levels and an attenuated cortisol awakening response.

\section{Methods}

\subsection{Participants}

Participants for the laboratory measurements were selected from those 222 (123 girls) fourth and 256 (137 girls) seventh graders from seven schools (five elementary and two middle schools) in a city in Finland who completed a survey questionnaire. The age groups were chosen according to the developmental saliency in transition from middle childhood to adolescence [32]. Altogether 88 subjects were stratified into fourth and seventh graders (10and 13-year-olds), and boys and girls.

Altogether 72 (33 girls, 39 boys; 39 10-year-olds, 33 13-year-olds) schoolchildren took part in the study. The dropouts were due to refusals and unwillingness to provide informed consent on the part of either the schoolchildren or their parents.

\subsection{Procedure}

Before data collection the approval of the Ethical Committee of Pirkanmaa Hospital District (Code Nr. R 04050) was acquired. Permission was also obtained from the school principals. At each school an information meeting was held, usually for each participating class separately, and an information letter was delivered both for the pupils selected for the study and their parents. Written consents for the participation were obtained from all children willing to participate, and their parent/guardian. The researcher gave directions for an activity diary and the subjects had possibility to ask questions.

At each school, in a peaceful room, the participants were given the saliva collection kits with verbal and written instructions. Children took their saliva samples during one day, and next day they returned the samples and the activity diary to the researcher. One day saliva samples of all the participants were collected during three weeks, from the end of April to the beginning of May. 
The sampling day was always an ordinary school day. As a reward for taking part in the study, the subjects received a cinema ticket each.

\subsection{Measures}

\subsubsection{Content and Intensity of ICT Use}

Exposure to ICT was measured by use of an activity diary covering the day preceding saliva sample collection. High subject compliance rate and data reliability have been obtained with diary method using objective measures as criterion, both among children and adolescents [33]. The participants were instructed to record in 15 minutes intervals the time spent on different ICT activities with alternatives 1) using mobile phone e.g. for phone calls, text messages, 2) playing mobile phone games, 3) playing TV or console games, 4) playing computer or Internet games, 5) using computer for homework, writing etc., 6) using computer for communication by e-mail, discussion groups, and chatting, and 7) general surfing on the Internet. Participants also recorded their sleeping hours, from going to bed until waking up the next morning. Total time spent on different ICT activities was calculated summing up the 15 min intervals for each activity. Child- reports on time they use for different activities have been shown to have moderately high validity [34].

\subsubsection{Salivary Cortisol}

Participants took five saliva samples (immediately at wakeup, at 1 hour after wake-up, at 3 hours after wake-up, late in the afternoon and before going to bed) using the Salivette sampling device (Salivette ${ }^{\circledR}$, Sarstedt, Germany). The Salivette tube consists of a plastic sampling vessel with a suspended insert containing a sterile neutral cotton wool swab that has to be chewed for about one minute and then returned to the insert. Children were instructed not to drink or eat or brush teeth half an hour before collecting the saliva sample. Salivary cortisol sampling compliance has shown to be reasonably high when verified electronically in adults [35]. The next day, the saliva samples were returned to the researcher and immediately mailed to the Finnish Institute of Occupational Health for cortisol assay. Free cortisol levels in saliva were measured using a commercially available chemiluminence assay (IBL, Hamburg, Germany).

\subsubsection{Pubertal Status}

In the survey questionnaire, pubertal status was measured by asking 'How old were you when you got your first period/spermarche?' The adolescents had to select one of the options: not yet, at the age of $10,11,12,13,14$, and 15 . For this study pubertal status was dummy coded: yes/ no at puberty.

\subsubsection{Depression}

In the survey questionnaire, depression was measured by depressive and anxiety symptoms. Six items indicating depressiveness were derived from the Child Depression Inventory CDI; [36], and included items such as "I am sad", "I cry easily and often" and "I feel that nobody cares about me". Five items indicating anxiety and fears were from the Screen for Anxiety Related Emotional Disorders 5-item SCARED; [37] and included items such as "I fear that something bad will happen to me", "Many things bother me", and "I fear that I will fail". The participants estimated how well the descriptions fitted them on a 5-point scale: (0) not at all, (1) somewhat, (2) quite well, (3) well, and (4) very well. The depressiveness and anxiety scales have been validated in a Finnish intervention study among children in depressive families [38]. Based on both scales a mean variable of depression was formed, and it had sufficient internal consistency of Cronbach's alpha 0.79 .

\subsection{Statistical Analysis}

For statistical analysis the participants were divided into two groups on the basis of the total sum of hours spent in different ICT activities during the day preceding saliva sample collection. Participants who had used ICT for less than one hour formed the low user group $(\mathrm{N}=42)$. In this group 32 participants (76\%) had not used ICT at all the day preceding salivary collection. The rest of the participants were called the user group $(\mathrm{N}=30)$. In the user group, the total time of ICT usage of 19 participants (63\%) was one to less than 3 hours, of six participants (20\%) 3 to less than 6 hours, and of five participants (17\%) 6-8 hours.

Differences between the ICT user groups in sex, age, classroom, and pubertal status were tested with Chisquare tests. Classroom was included in these analyses to be sure that the groups did not differ systematically according to the amount of ICT use or any other activity during the school day preceding cortisol measurements. Independent-samples t-tests were used to test group differences in depression, time spent in different ICT activities, wake-up time, sleeping hours before sampling, salivary sample times, and single salivary cortisol values. Group differences in daytime cortisol profiles were tested with general linear model (GLM) where five cortisol measures were within-subject repeated measures, and sex, level of depression and pubertal status were as covariates. Greenhouse-Geisser correction was applied because the assumption of sphericity was violated. Preliminary analysis indicated that girls showed significantly higher awakening cortisol levels than boys $(\mathrm{t}(70)=2.22, \mathrm{p}=0.030)$ but cortisol values did not differ by age and pubertal status and were not correlated with the level of depression.

In addition to short daytime cortisol profiles, areas under the curve with respect to ground $\left(\mathrm{AUC}_{\mathrm{G}}\right)$ and with respect to increase $\left(\mathrm{AUC}_{\mathrm{I}}\right)$ based on five measurements were computed according to the formula described by Pre- 
ussner, Kirschbaum, Meinlschmid, and Hellhammer [39]. These data were analysed with one-way ANCOVA using sex, the level of depression and pubertal status as covariates.

\section{Results}

\subsection{Descriptive Statistics}

The sample characteristics and the data for the two ICT user groups are summarised in Table 1. The low user and user groups did not differ by sex, age, classroom, level of depression or pubertal status. Participants in the user group differed significantly from the low user group both in the total time used ICT and in using different form of ICT except for mobile phone use. Hours slept before the salivary sampling, waking time, and sampling times did not differ between the ICT user groups.

\subsection{Relations between ICT Use and Salivary Cortisol}

The focus of the study was to examine the relation of the amount of time used on ICT to next-day salivary cortisol. In Table $\mathbf{1}$ are shown group values for the different corti sol measures. The sample 2 cortisol value tended to be higher in the low user group than in the user group. Analysis of the short daytime cortisol profiles revealed no significant difference between the groups $(\mathrm{F}(3.22,215.90)=$ 1.58; $p=0.191$ ) (Figure 1). The total cortisol level indicated by $\mathrm{AUC}_{\mathrm{G}}$ tended to be higher in the low user group than in the user group ( $p=0.09$ ). A sig nificant group difference was found in $\mathrm{AUC}_{\mathrm{I}}$. As expected,the user group showed a significantly reduced awakening response compared to the low user group $(p=0.03)$ although the effect size was relatively small.

Table 1. Demographic characteristics, intensity of using information and communication technology (ICT), time of saliva collection, and salivary cortisol values in low ICT user and ICT user groups

\begin{tabular}{|c|c|c|c|}
\hline \multirow[b]{2}{*}{ Variable } & \multicolumn{3}{|c|}{ Intensity of ICT-usage } \\
\hline & $\begin{array}{l}\text { Low } \text { user }^{1} \\
(\mathrm{~N}=42)\end{array}$ & $\begin{array}{c}\text { User }^{1} \\
(\mathrm{~N}=30)\end{array}$ & Statistic \\
\hline Sex (girl/boy) & $20 / 22$ & $14 / 16$ & $\chi^{2}(1,72)=0.00 ; p=0.990$ \\
\hline Age-group (10/13) & $21 / 19$ & $15 / 15$ & $\chi^{2}(1,72)=.24 ; p=0.624$ \\
\hline Classroom (17 classrooms) & $\begin{array}{l}0-6 \text { students/ } \\
\text { classroom }\end{array}$ & $\begin{array}{l}0 \text {-4 students/ } \\
\text { classroom }\end{array}$ & $\chi^{2}(16,72)=17.70, p=0.342$ \\
\hline Depression & $7.86(7.43)$ & $9.00(7.29)$ & $\mathrm{t}(71)=-0.649 ; \mathrm{p}=0.518$ \\
\hline \multicolumn{4}{|l|}{ Hours used on ICT by activity } \\
\hline Mobile phone calls, text messages & $15(0.29)$ & $0.17(0.38)$ & $\mathrm{t}(71)=-0.27 ; \mathrm{p}=0.786$ \\
\hline Mobile phone games & $01(0.05)$ & $09(0.30)$ & $\mathrm{t}(71)=-1.73 ; \mathrm{p}=0.088$ \\
\hline Playing TV and console games & $04(0.13)$ & $56(1.20)$ & $\mathrm{t}(71)=-2.81 ; \mathrm{p}=0.006$ \\
\hline Playing computer games & $05(0.17)$ & $1.16(1.89)$ & $\mathrm{t}(71)=-3.85 ; \mathrm{p}=0.000$ \\
\hline Using computer for writing, homework & $01(0.04)$ & $37(0.88)$ & $\mathrm{t}(71)=-2.69 ; \mathrm{p}=0.009$ \\
\hline $\begin{array}{l}\text { Using computer for } \\
\text { communication }\end{array}$ & $02(0.09)$ & $37(0.89)$ & $\mathrm{t}(71)=-2.53 ; \mathrm{p}=0.014$ \\
\hline Surfing in the Internet & $00(0.00)$ & $52(1.26)$ & $\mathrm{t}(71)=-2.71 ; \mathrm{p}=0.009$ \\
\hline Total hours of ICT usage & $14(0.26)$ & $3.15(2.52)$ & $\mathrm{t}(71)=-7.80 ; \mathrm{p}=0.000$ \\
\hline Wake-up time (h) & $0648(0054)$ & 0707 (0055) & $\mathrm{t}(71)=-1.63 ; \mathrm{p}=0.108$ \\
\hline $\begin{array}{l}\text { Sleeping hours before } \\
\text { sampling }\end{array}$ & $8.60(1.04)$ & $8.98(1.27)$ & $\mathrm{t}(71)=-1.39 ; \mathrm{p}=0.170$ \\
\hline \multicolumn{4}{|l|}{ Time of saliva collection (h) } \\
\hline Sample 1 & $0655(0036)$ & 0649 (0037) & $\mathrm{t}(71)=0.53 ; \mathrm{p}=0.596$ \\
\hline Sample 2 & $0758(0036)$ & $0754(0050)$ & $\mathrm{t}(71)=0.26 ; \mathrm{p}=0.794$ \\
\hline Sample 3 & $1010(0042)$ & $1001(0049)$ & $\mathrm{t}(71)=0.90 ; \mathrm{p}=0.372$ \\
\hline Sample 4 & $1528(0100)$ & $1553(0114)$ & $\mathrm{t}(71)=-1.58 ; \mathrm{p}=0.118$ \\
\hline Sample 5 & $2103(0316)$ & $2057(0400)$ & $\mathrm{t}(71)=0.11 ; \mathrm{p}=0.913$ \\
\hline \multicolumn{4}{|l|}{ Salivary cortisol (nmol/l) } \\
\hline Sample 1 & $18.28(8.55)$ & $20.32(7.86)$ & $\mathrm{t}(71)=-1.03 ; \mathrm{p}=0.308$ \\
\hline Sample 2 & $23.14(17.87)$ & $17.27(7.88)$ & $\mathrm{t}(71)=1.68 ; \mathrm{p}=0.097$ \\
\hline Sample 3 & $16.24(19.06)$ & $10.94(9.07)$ & $\mathrm{t}(71)=1.41 ; \mathrm{p}=0.163$ \\
\hline Sample 4 & 11.22 (13.49) & $7.91(8.27)$ & $\mathrm{t}(71)=1.19 ; \mathrm{p}=0.237$ \\
\hline $\mathrm{AUC}_{\mathrm{I}}$ & $-79.95(142.83)$ & $-201.59(175.68)$ & $\begin{array}{l}F(1,70)=4.82, p=0.032 \\
\eta^{2}=0.067\end{array}$ \\
\hline
\end{tabular}

${ }^{1}$ For sex, age group and puberty, frequency; for others, mean (standard deviation). $\mathrm{AUC}_{\mathrm{G}}$, area under curve with respect to ground; AUC , area under curve with respect to increase. Samples: $1=$ at wake-up, 2 = at 1 hour after wake-up, $3=$ at 3 hours after wake up, $4=$ late afternoon, $5=$ before going to bed 


\section{Discussion}

This study provides support for a link between time used ICT and next-day salivary cortisol pattern among schoolchildren. As expected, the participants who had used ICT on the average for three hours the preceding day showed a significantly reduced cortisol awakening response compared to those most of whom had used ICT not at all. This is in line with earlier results which show attenuated cortisol awakening response in relation to stress [19, 26-29].

In measuring cortisol different confounding factors have been identified, most of which, however, have been controlled in our study. According to earlier results both cortisol levels and the cortisol awakening response of 10-12-year-old children show seasonal variability, being highest during summer months [23] which may be related to greater amount of light [40]. Further, greater response has been reported on weekdays compared to weekends both by working adults [41] and children in day-care [15]. This kind of anticipation of a potentially stressful day has been observed in school-aged children, too [42]. In our sampling times there was no seasonal variation, and the sample collection day was always a weekday. Moreover, although earlier findings about the influence of awakening time on cortisol secretion are somewhat mixed [20], some recent studies imply that awakening time may be a confounding variable $[43,44]$. In this study, participants in the two ICT user groups did not differ according to waking-time or sleeping hours before salivary sampling, nor by sex, age, pubertal status or depression.

Measurement of salivary cortisol, compared to serum cortisol, has the advantage of a non-invasive and stressfree sampling procedure in the subjects' natural environment [23]. However, when saliva samples are collected in a domestic setting, the accuracy of the meas urements depends on participant adherence to the instructions [45]. Since no electronic monitoring was used, we have no means to objectively assess participants' com pliance to saliva sampling in this study. However, we have no reason to believe that the ICT users were less compliant than the

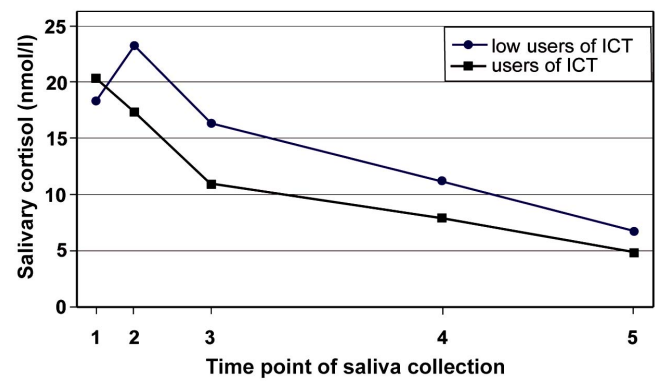

Figure 1. Salivary cortisol daytime profiles $(1=$ at wake-up, 2 = at 1 hour after wake-up, $3=$ at 3 hours after wake-up, 4 = late afternoon, 5 = before going to bed) in the low ICT user group $(\mathrm{N}=42)$ and ICT user group $(\mathrm{N}=30)$ other participants. Cortisol level is usually at its highest at 30 minutes after awakening. Had this measurement included, the cortisol level in the low user group might have been even higher during the second sample.

Generally, an altered cortisol awakening response is seen as an indicator of stress and stress-related changes in HPA-regulation. Adolescents rarely describe gaming and surfing in the Internet as stressing activities but, instead, as a way of passing time, getting positive experiences, and social communication. Gaming, Internet surfing, and other computer-based activities demand e.g. applying rules and strategies, quick reactions, and processing a lot of new information and experiences. Thus, in spite of the pleasant content, long period of focusing attention to game playing or Internet surfing may result in attention overload and directed attention fatigue [26]. Results have shown that subjective appraisals of stress and physiological reactions do not always mach $[46,47]$. Besides directed attention fatigue, strong emotions may be associated with game and Internet contents, social communication, and successes and failures around these activities. Emotional processes involve both the subjective feelings of the individual and the neural and biochemical basis $[9,30]$. Thus, strong emotions are another possible source of physiological stress. Earlier results show physiological stress reactions immediately after a play session [30]. Our results suggest that a psycho physiological load due to ICT use can persist over night and have an impact on the regulation of HPA-activity even the next morning. Part of the participants in the user group had spent 1-3 hours on ICT which could be seen quite a moderate and usual amount of ICT usage per day at present. An experimental design would be needed to examine does even quite a moderate period of ICT use alone or only when combined with school work have an impact on diurnal cortisol secretion. The possibility of the low user group to recover and restore after school work may be as important as directed attention fatigue in the ICT user group in explaining group differences.

According to our results salivary cortisol may be a variable of interest when studying stress, strain and restoration in connection with ICT use. Some methodological questions need to be addressed, however. The result should be replicated in other, possibly larger samples, including salivary cortisol measurement at 30 minutes after awakening. Electronic monitoring of wake-up time and saliva sampling, and more objective estimates of time spent in different activities would be advantageous. Inclusion of more than one day would allow assessment of cortisol baseline values and enable measurement of withinsubject differences based on ICT use. There are no standards for measuring pubertal development, but the selection of the method depends on which aspect of the puberty may be the most relevant to the research question [48]. In the current study, we were interested in the physical processes related to puberty which could affect 
the diurnal cortisol secretion, not e.g. social or psychological development. Especially menarche appears quite late in the pubertal development [48]. Thus, a more finegrained measure of stage of pubertal development [49] could be used.

In conclusion, our results suggest that long hours on ICT may imply stress responses during which the physiological regulation system is in imbalanced allostatic state [50]. Excessive use of ICT can be seen as a modern form of Type 2 allostatic load which refers to an individual's capacity to cope in the surrounding social context. It seems possible that long hours of ICT use day after day might work like a naturally occurring stressor, which would predispose some adolescents to the development of allostatic load. Stress from different sources may also have interactive effects [51]. In the face of multiple stressors, for instance, problems in family or peer relations, troubles at school, or living in a noisy or crowded environment, the negative effects of intensive ICT use may be strengthened. Turner-Cobb [50] suggests that under naturalistic conditions even changes within the normal range may be subtle early indicators of, and contributors to, physical health outcomes in adulthood.

Directed attention fatigue can be defined as an insufficient reserve of attention to perform demanding tasks [52]. In addition to physiological signs of stress, negative after-effects have also been observed in next-day performance [53]. It would be urgent to study whether excessive ICT use in the evening negatively affects adolescents' next-day school performance, for instance, in the form of poorer attention, persistence, or memory. There is evidence that changes in cortisol levels are associated with impaired cognitive performance, such as memory [54].

\section{Acknowledgements}

We are grateful to the schools for cooperation and to the children and adolescents who participated in the study. We thank Heli Sistonen, Jukka Koskelo, and Marjatta Radecki for assistance in data collection and Mrs. Marja Vajaranta and Virginia Mattila for language checking.

\section{REFERENCES}

[1] D. A. Christakis, B. E. Ebel, F. P. Rivara and F. J. Zimmerman, "Television, Video, and Computer Game Usage in Children Under 11 Years of Age,” The Journal of Pediatrics, Vol. 145, No. 5, 2004, pp. 652-656.

[2] D. F. Roberts, "Media and Youth: Access, Exposure, and Privatizaton," Journal of Adolescent Health, Vol. 27, No. 2, 2000, pp. 8-14.

[3] R.-L. Punamäki, M. Wallenius, C.-H. Nygård, L. Saarni and A. Rimpelä, "Use of Information and Communication Technology (ICT) and Perceived Health In Adolescence: The Role of Sleeping Habits and Waking-Time Tired- ness,” Journal of Adolescence, Vol. 30, No. 4, 2007, pp. 660-670.

[4] M. Wallenius, A. Rimpelä, R.-L. Punamäki and T. Lintonen, "Digital Game Playing Motives among Adolescents. Relation to Parent-Child Communication, School Performance, Sleeping Habits, and Perceived Health,” Journal of Applied Developmental Psychology, Vol. 30, No. 4, 2009, pp. 463-474.

[5] S. McNamee, "Foucaults's Heterotopia and Children's Everyday Lives,” Childhood, Vol. 4, No. 4, 2000, pp. 479-492.

[6] S. Lenot-Ledunois, G. Vardon, P. Perruchet and J. Gallego, "The Effects of Attentional Load on the Breathing Pattern in Children," International Journal of Psychophysiology, Vol. 29, No. 1, 1998, pp. 13-21.

[7] J. A. Veltman and A. W. Gaillard, "Physiological Workload Reactions in Increasing Levels of Task Difficulty," Ergonomics, Vol. 41, No. 5, 1998, pp. 656-669.

[8] S. Kaplan, “The Restorative Benefits of Nature: Toward an Integrative Framework," Journal of Environmental Psychology, Vol. 15, No. 3, 1995, pp. 169-182.

[9] U. Lundberg, B. Melin, G. W. Evans and L. Holmberg, "Physiological Deactivation after Two Contrasting Tasks at a Video Display Terminal: Learning vs. Repetitive Data Entry,” Ergonomics, Vol. 36, No. 6, 1993, pp. 601-611.

[10] S. Hérbert, R. Béland, O. Dionne-Fournelle, M. Crête and S. J. Lupien, "Physiological Stress Response to VideoGame Playing: The Contribution of Built-in Music," Life Sciences, Vol. 76, No. 20, 2005, pp. 2371-2380.

[11] G. Felsten, "Where to Take a Study Break on the College Campus: An Attention Restoration Theory Perspective," Journal of Environmental Psychology, Vol. 29, No. 1, 2009, pp. 160-167.

[12] J. F. Lopez, H. Akil and S. J. Watson, "Neural Circuits Mediating Stress,” Biological Psychiatry, Vol. 46, No. 1, 1999, pp. 1461-1471.

[13] G. W. Evans and L. A. Marcynyszyn, "Environmental Justice, Cumulative Environmental Risk, and Health among Low and Middle-Income Children in Upstate New York,” American Journal of Public Health, Vol. 94, No. 11, 2004, pp. 1942-1944.

[14] S. J. Lupien, S. King, M. J. Meaney and B. S. McEwen, "Can Poverty Get Under Your Skin? Basal Cortisol Levels and Cognitive Function in Children from Low and High Socioeconomic Status,” Development and Psychopatology, Vol. 13, No. 3, 2001, pp. 653-676.

[15] A. Dettling, M. R. Gunnar and B. Donzella, "Cortisol Levels of Young Children in Full-Day Childcare Centers: Relations with Age and Temperament," Psychoneuroendocrinology, Vol. 24, No. 5, 1999, pp. 519-536.

[16] A. K. Goenjian, et al., "Hypothalamic-Pituitary-Adrenal activity among American Adolescents with PTSD Symptoms," Journal of Traumatic Stress, Vol. 16, No. 4, 2003, pp. 319-323.

[17] M. Carlson, et al., "Effects of Social Deprivation on Cortisol Regulation in Institutionalized Romanian Infants," 
Society of Neuroscience Abstracts, Vol. 218, No. 12, 1995, p. 524.

[18] M. Lindahl, T. Theorell and F. Lindblad, "Test Performance and Self-Esteem in Relation to Experienced Stress in Swedish Sixth and Ninth Graders-Saliva Cortisol Levels And Psychological Reactions to Demands," Acta Paediatrica, Vol. 94, No. 4, 2005, pp. 489-495.

[19] W. Kliewer, "Violence Exposure and Cortisol Responses in Urban Youth," International Journal of Behavioral Medicine, Vol. 13, No. 2, 2006, pp. 109-120.

[20] A. Clow, L. Thorn, P. Evans and F. Hucklebridge, "The Awakening Cortisol Response: Methodological Issues and Significance,” Stress, Vol. 7, No. 1, 2004, pp. 29-37.

[21] S. Wust, J. Wolf, D. H. Hellhammer, I. Federenko, N. Schommer and C. Kirschbaum, "The Cortisol Awakening Response-Normal Values and Confounds," Noise and Health, Vol. 2, No. 7, 2000, pp. 79-99.

[22] U. Knutsson, et al., "Circadian Cortisol Rhythms in Healthy Boys and Girls: Relationship with Age, Growth, Body Composition, and Pubertal Development," Journal of Clinical Endocrinology and Metabolism, Vol. 82, No. 2, 1997, pp. 536-540.

[23] J. G. M. Rosmalen, A. J. Oldehinkel, J. Ormel, A. F. de Winter, J. K. Buitelaar and F. C. Verhulst, "Determinants of Salivary Cortisol Levels in 10-12 Year Old Children: A Population-Based Study of Individual Differences," Psychoneuroendocrinology, Vol. 30, No. 5, 2005, pp. 483495.

[24] E. K. Adam, “Transactions among Adolescent Trait and State Emotion and Diurnal and Momentary Cortisol Activity in Naturalistic Setting," Psychoneuroendocrinology, Vol. 31, No. 5, 2006, pp. 664-679.

[25] S. Edwards, A. Clow, P. Evans and F. Hucklebridge, "Exploration of the Awakening Cortisol Response in Relation to Diurnal Cortisol Secretory Activity,” Psychoneuroendocrinology, Vol. 26, No. 6, 2001, pp. 613-622.

[26] J. Gaab, L. Sonderegger, S. Scherrer and U. Ehlert, "Psychoneuroendocrine Effects of Cognitive-Behavioral Stress Management in a Naturalistic Setting-A Randomized Controlled Trial," Psychoneuroendocrinology, Vol. 31, No. 4, 2006, pp. 428-438.

[27] M. Wessa, N. Rohleder, C. Kirschbaum and H. Flor, “Altered Cortisol Awakening Response in Posttraumatic Stress Disorder,” Psychoneuroendocrinology, Vol. 31, No. 2, 2006, pp. 209-215.

[28] A. D. Roberts, S. Wessely, T. Chalder, A. Papadopuolod and A. J. Cleare, "Salivary Cortisol Response to Awakening in Chronic Fatigue Syndrome,” British Journal of Psychiatry, Vol. 184, No. 2, 2004, pp. 136-141.

[29] G. Meinlschmid and C. Heim, "Decreased Cortisol Awakening Response after Early Loss Experience,” Psychoneuroendocrinology, Vol. 30, No. 6, 2005, pp. 568- 576.

[30] L. M. Fulgham, "Effects of Videogame Play in Boys: An Examinaion of Adrenocortical Activity and Behaviour," Dissertation Abstracts International: Section B: The Sciences \& Engineering, Vol. 64 (2-B), No. 2, 2003, pp. 983.
[31] S. Denot-Ledunois, G. Vardon, P. Perruchet and J. Gallego, "The Effects of Attentional Load on the Breathing Pettern in Children,” International Journal of Psychophysiology, Vol. 29, No. 1, 1998, pp. 13-21.

[32] L. Steinberg and A. S. Morris, “Adolescent Development," Annual Review of Psychology, Vol. 52, No. 1, 2001, pp. 83-110.

[33] E. Thieden, P. A. Philipsen and H. C. Wulf, "Compliance and Data Reliability in Sun Exposure Studies with Diaries and Personal, Electronic UV Dosimeters," Photodermatology, Photoimmunology \& Photomedicine, Vol. 22, No. 2, 2006, pp. 93-99.

[34] T. H. A. Van der Voort and M. W. Vooijs, "Validity of Children's Direct Estimates of Time Spent Television Viewing,” Journal of Broadcasting \& Electronic Media, Vol. 34, No. 1, 1990, pp. 93-99.

[35] J. Jacobs, N. A. Nicolson, C. Derom, P. Delespaul, J. Van Os and I. Myin-Germeys, "Electronic Monitoring of Salivary Cortisol Sampling Compliance in Daily Life," Life Sciences, Vol. 76, No. 21, 2005, pp. 2431-2443.

[36] M. Kovacs, “Children's Depression Inventory,” Multihealth Systems, New York, 1992.

[37] B. Birmaher, "Psychometric Properties of the Screen for Child Anxiety Related Emotional Disorders (SCARED): A Replication Study," Journal of the American Academy of Child and Adolescent Psychiatry, Vol. 38, No. 4, 1999, pp. 1230-1236.

[38] T. Solantaus and S. Toikka, "The Efficient Family: An Intervention Study on the Prevention of Mental Disorders in Children with Affectively Ill Parents,” Juvenes Print, Tampere 2005.

[39] J. C. Preussner, C. Kirschbaum, G. Meinlschmid and D. H. Hellhammer, "Two Formulas for Computation of the Area Under the Curve Represent Measures of Total Hormone Concentration Versus Time-Dependent Change," Psychoneuroendocrinology, Vol. 28, No. 7, 2003, pp. 916931.

[40] F. A. J. L. Scheer and R. M. Buijs, "Light Affects Morning Salivary Cortisol in Humans," Journal of Clinical Endocrinology and Metabolism, Vol. 84, No. 9, 1999, pp. 3395-3398.

[41] S. R. Kunz-Ebrecht, C. Kirschbaum, M. Marmot and A. Steptoe, "Differences in Cortisol Awakening Response on Work Days and Weekends in Women and Men from the Whitehall II Cohort,” Psychoneuroendocrinology, Vol. 29, 2004, pp. 516-528.

[42] J. Bruce, E. P. Davis and M. R. Gunnar, "Individual Differences in Children's Cortisol Reponse to the Beginning of a New School Year,” Psychoneuroendocrinology, Vol. 27, No. 6, 2002, pp. 635-650.

[43] B. M. Kudielka and C. Kirschbaum, “Awakening Cortisol Responses are Influenced by Health Status and Awakening Time but not by Menstrual Cycle Phase," Psychoneuroendocrinology, Vol. 28, No. 1, 2003, pp. 35-47.

[44] I. Federenko, S. Wust, D. H. Hellhammer, R. Dechoux, R. Kumsta and C. Kirschbaum, "Free Cortisol Awakening 
Responses are Influenced by Awakening Time,” Psychoneuroendocrinology, Vol. 29, No. 2, 2004, pp. 179-184.

[45] J. E. Broderick, D. Arnold, B. M. Kudielka and C. Kirschbaum, "Salivary Cortisol Sampling Compliance: Comparison of Patients and Healthy Volunteers," Psychoneuroendocrinology, Vol. 29, No. 5, 2004, pp. 636-650.

[46] R. J. Davidson and W. Irwin, "The Functional Neuroanatomy of Emotion and Affevtive Style," Trends in Cognitive Science, Vol. 3, No. 1, 1999, pp. 11-21.

[47] A. R. Damasio, “A Second Chance for Emotions,” In: R. D. Lane and L. Nadel, Eds., Oxford University Press, New York, 2000, pp. 12-13.

[48] L. D. Dorn, R. E. Dahl, H. R. Woodward and F. Biro, "Defining the Boundaries of Early Adolescence: A User's Guide to Assessing Pubertal Status and Pubertal Timing in Research With Adolescents," Applied Developmental Science, Vol. 10, No. 1, 2006, pp. 30-56.

[49] J. M. Tanner and R. H. Whitehouse, "Atlas of Children's Growth: Normal Variation and Growth Disorders,” Academic Press, London, 1982.
[50] J. M. Turner-Cobb, "Psychological and Stress Hormone Correlates In Early Life: A Key to HPA-Axis Dysregulation and Normalisation,” Stress, Vol. 8, No. 1, 2005, pp. 47-57.

[51] R. M. Sapolsky, "Why Stress is Bad for Your Brain," Science, Vol. 273, No. 5276, 1996, pp. 749-750.

[52] G. W. Evans, K. M. Allen, R. Tafalla and T. O’Meara, "Multiple Stressors: Performance, Psychophysiological and Affective Responses," Journal of Environmental Psychology, Vol. 16, 1996, pp. 147-154.

[53] S. J. Lupien, C. W. Wilkinson, S. Briere, C. Menard, N. M. N. Y. Kin and N. P. Nair, "The Modulatory Effects of Corticosteroids on Cognition: Studies in Young Human Populations,” Psychoneuroendocrinology, Vol. 27, No. 3, 2002, pp. 401-416.

[54] B. S. McEwen and J. C. Wingfield, "The Concept of Allostasis in Biology and Biomedicine," Hormones and Behavior, Vol. 43, No. 1, 2003, pp. 2-15. 